\title{
Membrane protein reconstitution for functional and structural studies
}

\author{
WANG LiGuo* \& TONGGU LiGe \\ Department of Biological Structure, University of Washington, Seattle, Washington 98195, USA
}

Received August 15, 2014; accepted October 27, 2014

\begin{abstract}
Membrane proteins are involved in various critical biological processes, and studying membrane proteins represents a major challenge in protein biochemistry. As shown by both structural and functional studies, the membrane environment plays an essential role for membrane proteins. In vitro studies are reliant on the successful reconstitution of membrane proteins. This review describes the interaction between detergents and lipids that aids the understanding of the reconstitution processes. Then the techniques of detergent removal and a few useful techniques to refine the formed proteoliposomes are reviewed. Finally the applications of reconstitution techniques to study membrane proteins involved in $\mathrm{Ca}^{2+}$ signaling are summarized.
\end{abstract}

membrane protein, reconstitution, $\mathrm{Ca}^{2+}$ signaling, $\mathrm{Ca}^{2+}$ mediators, $\mathrm{Ca}^{2+}$-regulated enzymes, $\mathrm{Ca}^{2+}$ transducers

Citation: Wang LG, Tonggu LG. Membrane protein reconstitution for functional and structural studies. Sci China Life Sci, 2015, 58: 66-74 doi: $10.1007 / \mathrm{s} 11427-014-4769-0$

Membrane proteins are essential for cellular life. They are involved in various critical biological processes, such as ion and solute transport (ion channels and transporter proteins), energy conversion (proteins for respiration and ATP synthesis), and cell signaling (e.g., G protein-coupled receptors and receptor kinases). Consequently about a quarter of the genes in most genomes encodes membrane proteins. Membrane proteins account for $70 \%$ of all known pharmacological targets and $50 \%$ of potential new drug targets due to their intimate involvement in a wide variety of diseases, including diabetes, cancer and neurological disorders [2].

As shown by both structural and functional studies, the membrane environment plays an essential role for membrane proteins [3-5]. It is better to study membrane proteins in their native environment (i.e., cell membranes). However, the result can be difficult to interpret due to the complexity of the native membranes and the interferences with other membrane constituents or other reactions. Therefore, recon-

*Corresponding author (email: LW32@uw.edu) stitution of purified membrane proteins into liposomes (proteoliposomes) has been developed and served as a powerful tool for elucidating both functional and structural aspects of membrane proteins. The reconstitution of membrane proteins into liposomes makes it possible to accurately control the factors (e.g., lipid composition, and interacting proteins) that may affect the functions of the target proteins. This approach has been employed successfully to study the function of various ion channels and receptors, such as sodium channels [6], potassium channels [7,8], calcium channels [9], and $\mathrm{IP}_{3} \mathrm{Rs}$ [10] assessed by measuring the movement of radioactive ions/calcium ions, or the change of membrane potentials.

Studies of membrane protein functions in reconstituted liposomes started in 1970 s by the pioneering work of Racker and colleagues [11-13]. In the past four decades, a large number of reconstitution methods have been developed and refined. It is difficult or impractical to list all the information published since Racker's pioneering work in a single review, thus the reader is directed to the excellent reviews 
concerning specific reconstitution methods or specific classes of membrane proteins [1,14-22]. It is the purpose of this article to review, after a brief introduction describing the interaction between lipids and detergents and the methods of preparing proteoliposomes, the applications of reconstitution techniques to study membrane proteins involved in $\mathrm{Ca}^{2+}$ signaling.

\section{Reconstitution strategies}

Reconstitution of membrane proteins into liposomes usually starts with the isolation of cellular membranes. The isolated membranes are dissolved in organic solvent (organic solvent-mediated reconstitution) or detergents (detergent mediated-reconstitution) [1]. Due to the exposure of membrane proteins to organic solvents (e.g., ether and pentane) in the organic solvent-mediated reconstitution process, the membrane proteins are often denatured. The denaturation plus the multilamellar nature and the osmotic fragility of the resulted proteoliposomes precludes detailed functional studies of the reconstituted proteins, thus precludes the general use of organic solvent-mediated reconstitution. The most successful and widely used strategy for membrane protein reconstitutions is the detergent-mediated reconstruction. In the standard procedure, purified membrane proteins in the presence of detergents are mixed with detergent solubilized lipids to form an isotropic solution of lipiddetergent-protein and lipid-detergent micelles. The detergent is then removed, resulting in the formation of liposomes with incorporated proteins (proteoliposomes). Despite the extensive use and diverse applications of reconstitution, it is striking to notice that the mechanism of reconstitution (i.e., insertion of membrane proteins into liposomes) is still not fully elucidated. The current understanding is not much different from that proposed by Rigaud and colleagues [1].

It is crucial to understand the properties of detergents for the study of membrane proteins. The importance of detergents should never be underestimated. However, it is impossible to describe all the chemical and physical properties and the interactions among detergents, lipids and membrane proteins in this review. Thus readers are directed to an excellent review by Seddon et al. [18] for the types and properties of detergents, comprehensive reviews for the interac- tion between lipids and detergents [1,22], and comprehensive reviews for the interaction between detergents and membrane proteins [23-25]. In this review, we will cover some basic properties of detergents, and the interaction between lipids and detergents.

Detergents are amphipathic molecules, which consist of a polar (or charged) head group and a hydrophobic tail. Based on the type of the head group, detergents can be classified into three groups: ionic (cationic or anionic), nonionic, and zwitterionic. Ionic detergents such as SDS interrupt protein-protein interactions thus denature proteins. Nonionic and zwitterionic detergents are considered mild when used to solubilize membrane proteins due to the preservation of the protein-protein interactions.

Detergent molecules start to self-associate and form micelles at a threshold of monomer concentration, which is called the critical micelle concentration (CMC). The CMCs of a few commonly used detergents are listed in Table 1. The concentration of detergent monomers stays constant above the CMC as more detergent is added to the solution; only the concentration of detergent micelles increases. In order to solubilize hydrophobic or amphipathic molecules, such as proteins and lipids, the detergent concentration must exceed the CMC.

It is well known that the binary lipid-detergent system behaves differently from those of the pure components. The addition of a membrane protein to the lipid-detergent mixture further complicates the interactions. Thus, detergent behavior, during and after protein extraction from a bilayer, will impact the isolation, characterization, and stability of membrane proteins. When considering the added effects of other components (salt, $\mathrm{pH}$, etc.), small changes in experimental conditions may give rise to detergent effects not expected from the pure detergent. This is also why the detergent-mediated reconstitution process is still not fully understood.

Although the lipid-detergent system is very simple compared with the lipid-detergent-protein system, it can serve as a starting point to understand the protein reconstitution process and the protein extraction process. The solubilization of pure phospholipid membranes by detergents involves three stages [1] (Figures 1 and 2). In Stage I, detergent monomers partition into lipid membranes (i.e., liposomes), which results in larger liposome size evidenced by the slight increase of the optical density. In Stage II, lipid

Table 1 Properties of common detergents [26]

\begin{tabular}{|c|c|c|c|c|}
\hline Detergent & Category & $\mathrm{Mw}(\mathrm{Da})$ & $\mathrm{CMC}\left(\mathrm{mmol} \mathrm{L}^{-1}\right)$ & Dialyzable \\
\hline Sodium dodecyl sulfate (SDS) & Ionic & 288 & $7-10$ & Yes \\
\hline Sodium cholate & Ionic & 431 & $13-15$ & Yes \\
\hline CHAPS & Zwitterionic & 615 & 6 & Yes \\
\hline Triton X-100 & Nonionic & 647 & $0.2-0.9$ & No \\
\hline n-Decyl- $\beta$-D-maltopyranoside (DM) & Nonionic & 483 & 1.8 & Yes \\
\hline Octyl glucoside (OG) & Nonionic & 292 & $23-25$ & Yes \\
\hline
\end{tabular}


membranes saturated with incorporated detergents begin to dissolve, which results in the coexistence of detergent-saturated liposomes and lipid-detergent micelles. In Stage III, lipid membrane is fully solubilized into lipid-detergent micelles. To extract membrane protein from cellular membranes, detergents are added, while to reconstitute membrane proteins into liposomes, detergents are removed. With regard to protein-lipid association during detergent removal from mixed binary and ternary micelles, there are three schemes as shown in Figure 1B. First of all, the reconstitution efficiency (i.e., whether the membrane protein is reconstituted into liposomes) depends strongly on the initial detergent concentration. For example, the reconstitution efficiency for detergent $C$ (blue curve in Figure 1B) is much higher at detergent concentration of Rsat than at detergent concentration of Rsol. Second, the reconstitution efficiency depends on the nature of the detergent used. As shown in Figure 1B, at point $\mathrm{P}$, the reconstitution efficiency with detergent $\mathrm{C}$ is higher than that with detergent $\mathrm{A}$. Also, the maximum reconstitution efficiency occurs at different detergent concentrations. Lastly, the reconstitution efficiency also depends on the membrane protein of interest, the composition of the lipids, the removal rate of detergent, the ionic conditions and the precise conditions of the initial detergent solubilization.

After reconstitution, there exist two populations: proteoliposomes and empty liposomes. The detailed mechanism was not fully understood yet. One mechanism was proposed by Rigaud and colleagues [1,27,28]. In the lipid/detergent/ protein system, there exist both binary (lipid-detergent) and ternary (lipid-detergent-protein) micelles. If detergent is removed rapidly, detergent is removed from both binary and ternary micelles, which results in a homogeneous population of vesicles, all having the average lipid-to-protein ratio. If the detergent is removed slowly, it is removed from ternary micelles preferentially, which results in protein-rich vesicles. This is supported by the observation that only the population of empty liposomes increased when lipid amount was increased for $\mathrm{Ca}^{2+}$-ATPase reconstitution [28]. However, this mechanism might not be applicable to other systems as the lipid-to-protein ratio was extremely high $(\sim 1: 2)$.

In detergent-mediated reconstitution process, membrane proteins can be inserted in two orientations: inside-out and outside-out. Young et al. [28] investigated the orientation of $\mathrm{Ca}^{2+}$-ATPase in the bilayer after reconstitution by determining the fraction of molecules accessible to fluorescein isothiocyanate (FITC), which undergoes a well-characterized reaction with Lys 515 in the cytoplasmic domain, thus abolishing the ATPase activity of $\mathrm{Ca}^{2+}$-ATPase. They found that $80 \%$ of $\mathrm{Ca}^{2+}$-ATPase face outward. Wang et al. [8] investigated the orientation of the human large-conductance calcium- and voltage-activated potassium channel (BK) using cryo-electron microscopy (cryo-EM). The orientation of each protein particle was determined computationally, and $\sim 70 \%$ of the BK channels were inserted inside-out. One
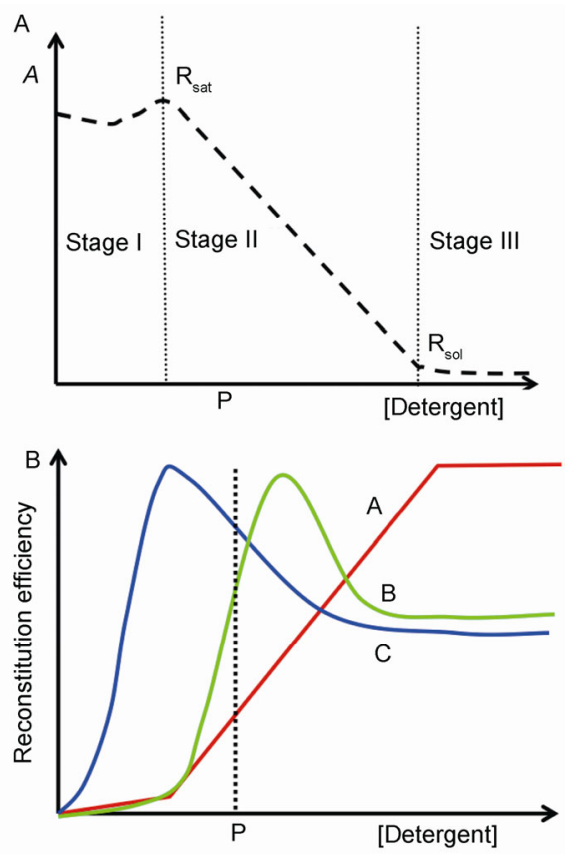

Figure 1 Schematic representation of the protein reconstitution mechanisms. A, Optical density $(A)$ of lipid-detergent suspension. B, Reconstitution efficiency of membrane proteins using detergent $\mathrm{A}, \mathrm{B}$ and $\mathrm{C}$. The main lipid phase is the lipid bilayer (liposomes) in stage I. Bilayers and micelles coexist in stage II, and stage III represents complete solubilization of lipid in mixed micelles. $\mathrm{R}_{\mathrm{sat}}$ and $\mathrm{R}_{\text {sol }}$ are the critical detergent-to-lipid ratios where the lipid phase changes from stages I to II, and II to III. Adapted from Rigaud et al. [1].

possible reason for more BK channels to be inserted inside-out might lie in the fact that about $2 / 3$ of the BK protein mass is in the large cytoplasmic domain. The inside-out orientation keeps the large intracellular domain outside of the liposome.

\section{Detergent-mediated reconstitution methods}

To reconstitute membrane proteins into liposomes, membrane proteins are purified and solubilized in detergents. Then protein/detergent mixture is mixed with lipid/ detergent mixture to form a homogeneous solution. A variety of methods can be used to remove detergents to form proteoliposomes.

\subsection{Detergent removal methods}

\subsubsection{Dilution}

Dilution is the simplest technique to remove detergents. By addition of the detergent-free diluting buffer, the total detergent concentration is lowered. When the total detergent concentration is lower than the detergent's CMC, proteoliposomes will form. This is the most suitable technique to control detergent removal and monitor vesicle reconstitution 

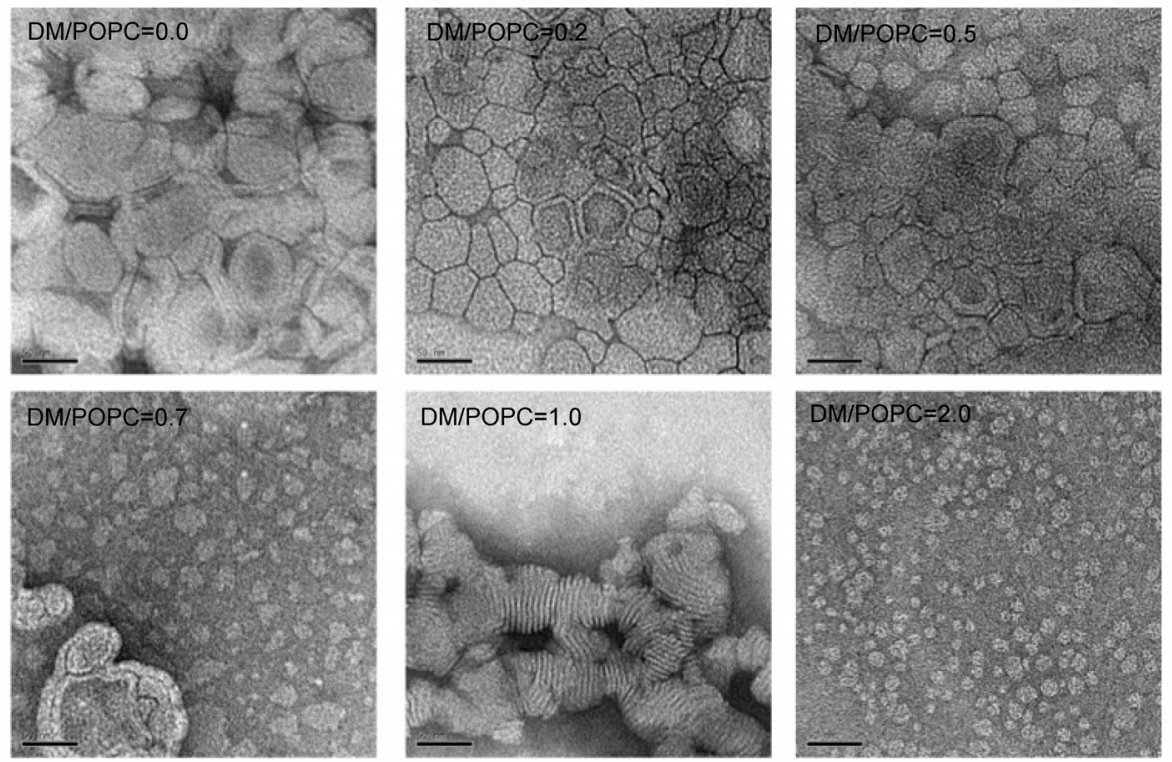

Figure 2 Negative staining electron microscopy images showing the interaction between lipid and detergent. DM was added to preformed POPC liposome solutions, and the sample was rotated at room temperature for $24 \mathrm{~h}$. Then $6 \mu \mathrm{L}$ of solution was applied to a glow discharged TEM grid coated with continuous carbon film, and stained with $2 \%$ Uranyl acetate. Scale bar, $50 \mathrm{~nm}$.

[29]. However, there are a few disadvantages: (i) at the addition point, the mixed micelles are directly exposed to the concentration of the diluting buffer, thus a large local inhomogeneity is created. (ii) Full detergent removal cannot be achieved, as it requires infinite dilution. (iii) The sample is highly diluted, thus extra concentration steps are needed.

\subsubsection{Biobeads}

As detergents are amphiphilic, they can bind to insoluble hydrophobic polymer beads (e.g., Biobeads SM2 or Amberlite $\mathrm{XAD}$ ) via the interaction of their hydrophobic tail with the hydrophobic surface of the bead [30]. After binding (i.e., physical adsorption) with the detergent-containing solution, the detergent-coated beads are removed by centrifugation or filtration. Because of the high binding capacity, this technique can be used to remove almost all kinds of detergents. This technique has been successfully employed to reconstitute $\mathrm{Ca}^{2+}$-ATPase [28], Type-IV P-type ATPases [31], rat heart mitochondrial F1Fo ATP synthase [32], and Multidrug Transporter LmrP Protein [33] into liposomes.

The detergent removal by biobeads is usually rapid (minutes to hours), and can be controlled by adding small numbers of beads at desired time intervals. There is a local detergent concentration gradient around the biobeads, which results in a large local inhomogeneity. To obtain more homogeneous liposomes, it is essential to maintain a low bead-to-detergent ratio used in the first step of reconstitution [1]. The rate of detergent removal determines the final size distribution of the reconstituted liposomes: small liposomes are formed by fast detergent removal, whereas large liposomes are formed by slow removal. Due to the hydro- phobic nature of these beads, lipids or proteins are adsorbed to biobeads inevitably. However, the adsorption of lipid has been shown to be two orders of magnitude lower than that of detergent [34]. It is mainly because the size of the mixed micelles is larger than the pore size of beads, which restricts the adsorption of micellar material only to the surface, whereas free detergent molecules can diffuse to the inside of biobeads.

\subsubsection{Dialysis}

Dialysis is one of the most common techniques to remove detergents. The lipid/detergent/protein mixture is dialyzing against detergent-free buffer (in 200-1000 fold excess) in a dialysis bag (high permeability cellulose membrane) with a cut-off of $\sim 10 \mathrm{kD}$ under slow stirring. This technique works best for detergents with high CMCs (unsuitable for detergents with low CMCs such as C12E8 or Triton X-100). Dialysis is a very gentle method, and is recommended when labile and unstable molecules are incorporated into liposomes. When synthetic lipids are used, the dialysis method has to be performed above the corresponding transition temperature $T c$ of the lipid. For example, a temperature above its $T c$ of $41^{\circ} \mathrm{C}$ has to be used when dipalmitoylphosphatidyl choline (DPPC) is used as a main component.

Despite the low cost of the materials used and the simplicity of this technique, there exist a few drawbacks: (i) uncontrolled detergent removal rate, thus poor reproducibility, (ii) unknown final sample concentration as the volume changes due to the osmotic pressure differences, (iii) long duration of dialysis due to the number of changes of buffer. 


\subsubsection{Gel filtration}

Gel filtration, also known as gel exclusion chromatography, is based on the size differences between mixed micelles and liposomes. Gel filtration uses a detergent-free buffer for elution. The molecular diffusion and faster access of the smaller aggregates (monomers, mixed micelles) to the gel pores result in the formation of liposomes. The resulting liposomes are excluded from the gel pores.

Gel filtration is simple, efficient, very fast (5-20 min using a Sephadex G-50 column), and highly reproducible. This technique has been successfully employed to reconstitute the human large-conductance calcium- and voltage-activated potassium channel (BK) [8], and glycophorin A [35] into liposomes. However, there are two drawbacks: (i) the sample is diluted after gel filtration, and extra concentration step might be needed, (ii) possible retention by the gel of lipid molecules ( $~ 50 \%$ loss of lipid in our lab).

\subsection{Additional processes (post-reconstitution processes)}

After the formation of proteoliposomes, occasionally further treatment is desired to change the proteoliposome size or change the liposome morphology (i.e., from multilamellar to unilamellar).

\subsubsection{Freeze-thaw}

It is well known that rehydration of dry lipids in aqueous buffer (lipid suspension) forms multilamellar vesicles (MLVs) with typical sizes of the order of a micron. The freeze-thaw technique is usually employed to break MLVs to form unilamellar vesicles [36,37]. Briefly, MLV solution in a glass tube is dipped into liquid nitrogen for rapid cooling. Then the frozen lipids are transferred to a water bath at $60^{\circ} \mathrm{C}$ for thawing. Usually this cycle is repeated about 10 times. More freeze-thaw cycles will result in smaller vesicles. However, if sonicated vesicles are used, freezethawing treatment causes fusion of sonicated unilamellar vesicles into larger vesicles [38]. This technique is sometimes complemented by filtration to obtain homogeneous vesicles, as the size of liposomes after freeze-thaw cycles is not uniform.

\subsubsection{Extrusion}

Extrusion is the widely used technique to obtain vesicles with a defined size distribution. Large multilamellar vesicles are forced to pass through polycarbonate filters with desired pore size (from 0.03 to $5 \mu \mathrm{m}$ pore diameter). Either Avanti Mini-Extruder (0.25 or $1.0 \mathrm{~mL}$ ) or Lipex ${ }^{\mathrm{TM}}$ extruder (1.5 or $10.0 \mathrm{~mL}$ ) can be used. Repetitive extrusion of multilamellar vesicles through filters with a $100 \mathrm{~nm}$ pore size or less results in the production of homogeneously sized unilamellar vesicles. However, filters with larger pore sizes (e.g., 200 and $400 \mathrm{~nm}$ in diameter) give rise to larger systems with increasingly multilamellar character [39]. It is recommended to combine the freeze-thaw and the extrusion techniques if unilamellar vesicles are needed.

\subsubsection{Sonication}

Lipid suspensions (multilamellar vesicles, MLVs) are exposed to sonic oscillation in a bath [40] or probe-tip sonicator [41], where acoustic energy is used to break MLVs to small unilamellar vesicles. The size of vesicles is dependent on the sonication setting, with the smallest radius around $10 \mathrm{~nm}$ [42]. This technique has been successfully employed to treat exchanger proteoliposomes [43].

\subsubsection{Gradient separation of proteoliposomes from empty liposomes}

After reconstitution, there usually exist two populations: proteoliposomes and protein-free liposomes. Based on the fact that the averaged density of proteoliposomes (between 1.03 and $1.05 \mathrm{~g} \mathrm{~cm}^{-3}$ [44]) is heavier than that of liposomes, a discontinuous gradient (e.g., metrizamide, Nycodenz, and sucrose), is used to separate these two populations (e.g., $100,000-200,000 \times g$ for 3-18 h). For example, protein-free liposomes were found in the $3 \%$ Nycodenz layer (10\% sucrose layer), while proteoliposomes appeared at the boundary between $5 \%$ and $15 \%$ Nycodenz layers (or $40 \%$ and $50 \%$ sucrose layers) $[8,28]$. The sucrose or Nycodenz could be removed by dialysis or repetitive dilution-concentration cycles.

\section{Application}

Calcium is involved in many critical biological processes, both intracellular [45,46] and extracellular [47]. As $\mathrm{Ca}^{2+}$ is an intracellular second messenger, the regulation of calcium concentration is critical. The physiological extracellular calcium concentration is around $1 \mathrm{mmol} \mathrm{L}^{-1}$, intracellular concentration around $0.1 \mu \mathrm{mol} \mathrm{L}{ }^{-1}$ and the largest $\mathrm{Ca}^{2+}$ store in cells is found in the ER or sarcoplasmic reticulum, with local $\mathrm{Ca}^{2+}$ concentrations at millimolar levels [48]. According to Harmon et al. [46], many membrane proteins sever as calcium mediators and calcium receptors, which control cytosolic calcium level and regulate extracellular calcium concentration respectively. Some membrane proteins are also involved in calcium signal transduction, including trimeric $\mathrm{G}$ protein, phospholipase $\mathrm{C}$ as calcium signal transducer and BK, PKC as calcium regulated enzymes and processes. Proteoliposomes are used to study structures and mechanisms for these signaling processes, as well as used in biomimetics [49-51] and cochleate drug delivery system [52-56]. Here, we summarize the studies that involve proteoliposome reconstitution in the field of $\mathrm{Ca}^{2+}$ signaling.

\subsection{Calcium mediators}

\subsubsection{Calcium channels}

(1) Receptor-operated channels (ROCs). Acetylcholine 
receptor was a milestone in the history of proteoliposome reconstitution. It was not only the first ion channel to be purified [57], but also the first channel to be functionally reconstituted in synthetic lipid bilayers [58,59]. Schiebler et al. showed that the biological function of acetylcholine receptors was observed when detergent was switched from mild detergent Triton X-100 to cruder detergent sodium cholate [59]. The protein solution was mixed with artificial lipid phophatidylcholine, phophatidylethanolamine, phosphatidylserine, sphingomyelin, phosphatidylinositol and cholesterol in the presence of sodium cholate. Gel filtration method was used to remove detergent and residual sodium cholate was further removed by dialysis. Proteoliposomes were fractionated by sucrose gradient before use. Functions of proteoliposomes were assessed by monitoring the release of $\mathrm{Na}^{+}$trapped inside liposomes after the addition of agonist carbamylcholine. Negative staining electron microscopy (EM) was employed to characterize the morphology of acetylcholine receptor-enriched vesicles. In a study shortly later [58], acetylcholine receptors were solubilized in detergent potassium cholate and mixed with soybean phospholipids. Proteoliposomes were formed by dialysis method. To measure $\mathrm{Na}^{+}, \mathrm{Rb}^{+}$and $\mathrm{Ca}^{2+}$ flux, the proteoliposomes were diluted in radiolabeled cation solutions using Dowex column with or without agonist cabamylcholine.

(2) Inositol-1,4,5-trisphophate receptors ( $\left.\mathrm{IP}_{3} \mathrm{Rs}\right) . \quad \mathrm{IP}_{3} \mathrm{Rs}$ were reconstituted into proteoliposomes for functional characterization [10,60,61]. Preformed liposomes were generated by sonication of soybean phospholipids (asolectin) suspension. $\mathrm{IP}_{3} \mathrm{Rs}$ were mixed with preformed liposomes in the presence of detergent CHAPS and detergents were removed by dialysis method. Functional study was carried out by varying $\mathrm{Ca}^{2+}$ concentration to test $\mathrm{Ca}^{2+}$-dependent inhibition of $\mathrm{IP}_{3} \mathrm{R}$ binding. Proteoliposomes were also fused into planar lipid bilayers for single channel recording.

(3) Voltage-operated channels (VOCs). In $\mathrm{Ca}^{2+}$ influx study for VOC [9], soybean phospholipids were suspended in aqueous buffer with detergent octyl glucoside and sonicated. Then the mixture was mixed with sarcolemmal membranes from fresh bovine heart left ventricle containing $\mathrm{Ca}^{2+}$ channels. Proteoliposomes were formed by dialysis method. After reconstitution, proteoliposomes were centrifuged, washed and resuspended in $\mathrm{K}^{+}$loading buffer, frozen and thawed, and sonicated before each use. Functions were assessed by monitoring the intensity change of fluorescence dye Quin2, which was loaded with $\mathrm{K}^{+}$loading buffer. $\mathrm{Ca}^{2+}$ influx was found to be dependent on membrane potential, enhanced by calcium channel agonist Bay K 8644, and inhibited by various calcium antagonists.

Bovine heart voltage-dependent L-type $\mathrm{Ca}^{2+}$ channels were also reconstituted into liposomes [62] by removing CHAPS via gel filtration. Sarcolemmal proteins comprising the $\mathrm{Ca}^{2+}$ channel protein were solubilized with CHAPS and mixed with soybean phospholipids. The proteoliposomes were formed by gel filtration. Membrane potential was clamped between -83 and $63 \mathrm{mV}$ by the potassium gradient across the lipid membrane and the potassium ionophore valinomycin. To measure $\mathrm{Ca}^{2+}$ efflux, fluorescence dye fura-2 was used. The results demonstrated that protein kinase $\mathrm{C}$ (PKC) failed to modulate $\mathrm{Ca}^{2+}$ efflux. Photoaffinity labeling of proteoliposomes was also used to measure the phosphorylation. The results demonstrated that protein kinase A (PKA) rapidly phosphorylated 210 and $170 \mathrm{kD}$ membrane proteins.

\subsection{2 $\mathrm{Ca}^{2+}$-pumps (aka $\mathrm{Ca}^{2+}$-ATPase)}

$\mathrm{Ca}^{2+}$ pumps remove $\mathrm{Ca}^{2+}$ from the cytosol during signaling events. ATPase in the sarcoplasmic reticulum membrane of skeletal muscle cells is the best-understood p-type transport ATPase. $\mathrm{Ca}^{2+}$-ATPase (an ATP-driven calcium pump that belongs to the family of P-type ion pumps) from sarcoplasmic reticulum was reconstituted into preformed egg PC/cholesterol (9:1) vesicles [63]. $\mathrm{Ca}^{2+}$-ATPases solubilized by detergent octyl glucoside were mixed with liposomes formed by sonication. Proteoliposomes were formed by dilution method and were further sonicated to generate smaller liposomes. Sucrose gradient was used to separate empty liposomes. Steady state electrical potentials across the membrane were clamped by using potassium gradients and valinomycin, and monitored with voltage-sensitive dyes. These findings suggest that the membrane voltage influences the coupling between $\mathrm{Ca}^{2+}$ transport and ATP hydrolysis. Sarcoplasmic reticulum $\mathrm{Ca}^{2+}$-ATPase was also reconstituted by Cheng et al. [64] with dialysis method. $\mathrm{Ca}^{2+}$-ATPases, egg PC and soybean PE phospholipids and detergent deoxycholate were mixed and proteoliposomes were formed by dialysis. After reconstitution, proteoliposomes were further treated with sucrose density gradient and sonicated before use. Calcium uptake was measured using arsenazo III. Calcium efflux was measured by adding ATP to the external solution. Freeze-fracture electron microscopy was used to characterize proteoliposomes. Wakabayashi and Shigekawa [65] employed freeze-thaw sonication procedures to reconstitute ATPase. Soybean phosphatidylcholine was sonicated. The ATPase protein was solubilized with detergent cholate at various cholate-to-protein ratios (w/w). An aliquot of the phospholipid suspension was mixed with this cholate/protein mixture. The mixture then was frozen in liquid $\mathrm{N}_{2}$, thawed at room temperature and sonicated. Calcium uptake by the reconstituted proteoliposomes was measured by membrane filtration method using radiolabeled calcium.

\section{2 $\mathrm{Ca}^{2+}$ transducers}

Trimeric G-protein serves as calcium signal transducer for animals. In Moffett's study [66], lipids phosphatidylcholine and cholesterol or phosphatidylcholine, phosphatidylethanolamine, sphingomyelin, cerebrosides, and cholesterol (SCRL) were mixed, dried and rehydrated. The lipid sus- 
pension was sonicated and then frozen and thawed three times. To incorporate proteins, freshly acylated $\mathrm{G}$ proteins (M/PGai or M/PGaibg), or mockacylated Gai, MGai, Gbg, and MGaibg were mixed with detergent CHAPS. The protein solution was then mixed with empty liposomes. The molar ratio of CHAPS:phospholipids is $\sim 0.72$ and only partial solubilization of the liposomes occurs. The mixture was then diluted stepwise at room temperature. Reconstitution efficiency and G-protein membrane partition were studied.

\section{3 $\mathrm{Ca}^{2+}$-regulated enzymes and processes}

\subsection{1 $\mathrm{Ca}^{2+}$-sensitive ion channels}

The large conductance calcium-activated potassium (BK, maxi-K) channel was reconstituted into liposomes by rapid dilution [67]. Phospholipid solution was prepared by evaporating solutions containing PE, PS, PC, and cholesterol. These lipids were then dispersed in reconstitution buffer by sonication. BK protein solubilized in Triton X-100 was mixed with these preformed liposomes and frozen and thawed twice in a dry-ice/ethanol bath, centrifuged and resuspended to enhance reconstitution efficiency. Before use, the aliquots were sonicated. Single channel recording was performed by fusing proteoliposomes into planar lipid bilayers.

In 2009, BK proteins were expressed in HEK293 cells and purified with anti-Flag affinity chromatography in the presence of detergent DM [8]. The protein solution was mixed with DM solubilized POPC lipids and the gel filtration method was used to remove detergent. The formed proteoliposomes were fractionated in Nycodenz gradient. The function of the reconstituted BK channels was assessed by monitoring the membrane potential with a voltage sensitive dye. The same BK proteoliposomes were also fast frozen and imaged using cryo-electron microscopy (cryo-EM). The structure of the BK channel in a lipid membrane environment has been determined.

\subsection{2 $\mathrm{Ca}^{2+}$-triggered exocytosis}

In the groundbreaking work by Weber et al. [68,69], reconstitution model system was used to study vesicle-vesicle fusion. Membrane protein VAMP2 (aka Synaptobrevin2) was used to form v-SNARE proteoliposomes, while syntaxin1A and synaptosome-associated protein of $25 \mathrm{kD}$ (SNAP25) were used to form t-SNARE proteoliposomes. Rapid dilution below the CMC of octyl glucoside was performed to form proteoliposomes, and dialysis was used to further remove detergents. Before use, density gradient was used to isolate proteoliposomes. The protein to lipid ratios (PLR) were $0.5(\mathrm{w} / \mathrm{w})$ and $3.0(\mathrm{w} / \mathrm{w})$ for v-SNARE and t-SNARE, respectively. Negative staining electron microscopy was used to characterize the size of vesicles, ranging from about 35 to $100 \mathrm{~nm}$ in diameter with a mean diameter of $45 \mathrm{~nm}$. Tracer radiolabeled phospholipids and an amido black protein assay were used to estimate protein copies per vesicle: about 750 copies of VAMP on a $45 \mathrm{~nm} \mathrm{v-SNARE}$ while 74 copies of syntaxin and 75 copies of SNAP25 on a $45 \mathrm{~nm}$ t-SNARE. Lipid mixing assay was carried out using NBD-PE and rhodamine-PE on v-SNARE and fluorescent signal change occurred when v-SNARE was mixed with t-SNARE in bulk. NBD fluorescence dye on the outer leaflets reacted with dithionite to eliminate hemifusion. Another content mixing assay based on complementary oligonucleotides inside of the liposomes was developed later [69].

In 2005 [70], the v-SNARE and t-SNARE vesicles were reconstituted by rapid dilution and dialysis to remove detergent octyl glucoside and subsequently purified by gradient separation. V-SNARE vesicles were reconstituted using a lipid mixture composed of 1-palmitoyl, 2-oleoyl phosphatidylcholine (POPC), 1,2-dioleoyl phosphatidylserine (DOPS), and $1 \%$ head-labeled $\mathrm{N}$-(tetramethylrhodamine)-1,2-diheptadecanoyl phosphatidylethanolamine. t-SNARE vesicles were reconstituted in POPC and DOPS. Docking and fusion of single proteoliposomes reconstituted with full-length v-SNAREs into planar lipid bilayers containing binary t-SNAREs was observed and measured separately in real time by wide-field fluorescence microscopy.

In a structural study of SNARE [71], t-SNARE or VAMP2 was reconstituted by mixing proteins with extruded liposomes. Briefly, DOPC and DOPS lipid in chloroform was dried in glass test tubes and resuspended in sodium phosphate buffer by vortexing vigorously. Unilamellar vesicles were formed by sonication, followed by a $50-\mathrm{nm}$ pore size extrusion. Two sets of proteoliposomes were prepared by gently mixing either t-SNARE complex or VAMP2 with liposomes, followed by freeze-thaw cycle three times to enhance protein reconstitution. Typically, vesicles (48-52 nm in diameter) were obtained as assessed by AFM and photon correlation spectroscopy. AFM and negative staining EM demonstrated the formation of 6-7 nm membrane-directed self-assembled t-/t-SNARE ring complexes.

\section{Conclusion and perspectives}

In the past 40 years, a large number of reconstitution methods have been developed and refined. Many membrane proteins have been successfully reconstituted to study their functions and structures. Despite the extensive use and diverse applications of reconstitution, it is surprising that the mechanism of liposome reconstitution (i.e., insertion of membrane proteins into liposomes) is still not fully understood. Fortunately, the lack of precise knowledge of the reconstitution mechanism does not prevent us from making proteoliposomes for functional and structural studies. However, there is always a concern whether the activity of membrane proteins is the same as that in cellular membrane environment due to the composition difference between the model lipid bilayer and the native cell membrane. Understanding of the behavioral changes for proteins in model 
membrane systems after membrane reconstitution is often a prerequisite to protein research. It is essential to find better solutions for retaining membrane protein activities for measurement and characterization in vitro.

To reconstitute membrane proteins into liposomes, membrane proteins are usually purified in the presence of detergents. Selecting the right detergent is crucial to the success of membrane protein purification and reconstitution, and is only a trial-and-error process. An understanding of the detergent parameters that determine membrane protein solubility and functionality is highly needed.

In detergent-mediated reconstitution process, there is no control of the proteoliposome size, which makes the interpretation of the experiment results complicated. It is better to reconstitute membrane proteins into pre-formed liposomes. To our best knowledge, the current practice always involves the mixing of detergent solubilized membrane proteins with pre-formed liposomes, which inevitably introduces detergent into the system and changes the size of liposomes. Then the mixture is treated by sonication or freeze-thaw methods, which further changes the size of liposomes. Further studies are needed to control the proteoliposome size.

This work was supported by US National Institutes of Health (R01GM096458) to Wang LiGuo.

1 Rigaud JL, Pitard B, Levy D. Reconstitution of membrane proteins into liposomes: application to energy-transducing membrane proteins. Biochim Biophys Acta Bioenerg, 1995, 1231: 223-246

2 Weinglass $\mathrm{AB}$, Whitelegge JP, Kaback HR. Integrating mass spectrometry into membrane protein drug discovery. Curr Opin Drug Dis Dev, 2004, 7: 589-599

3 Long SB, Tao X, Campbell EB, MacKinnon R. Atomic structure of a voltage-dependent $\mathrm{K}^{+}$channel in a lipid membrane-like environment. Nature, 2007, 450: 376-383

4 Gonen T, Cheng Y, Sliz P, Hiroaki Y, Fujiyoshi Y, Harrison SC, Walz T. Lipid-protein interactions in double-layered two-dimensional AQP0 crystals. Nature, 2005, 438: 633-638

5 Schmidt D, Jiang QX, MacKinnon R. Phospholipids and the origin of cationic gating charges in voltage sensors. Nature, 2006, 444: $775-779$

6 Tanaka JC, Eccleston JF, Barchi RL. Cation selectivity characteristics of the reconstituted voltage-dependent sodium channel purified from rat skeletal muscle sarcolemma. J Biol Chem, 1983, 258: 7519-7526

7 Brohawn SG, del Mármol J, MacKinnon R. Crystal structure of the human K2P TRAAK, a lipid- and mechano-sensitive $\mathrm{K}^{+}$ion channel. Science, 2012, 335: 436-441

8 Wang L, Sigworth FJ. Structure of the BK potassium channel in a lipid membrane from electron cryomicroscopy. Nature, 2009, 461: 292-295

9 Nakao S, Ebata H, Hamamoto T, Kagawa Y, Hirata H. Solubilization and reconstitution of voltage-dependent calcium-channel from bovine cardiac-muscle. $\mathrm{Ca}^{2+}$ influx assay using the fluorescent dye Quin2. Biochim Biophys Acta, 1988, 944: 337-343

10 Ramos-Franco J, Bare D, Caenepeel S, Nani A, Fill M, Mignery G. Single-channel function of recombinant type 2 inositol 1,4,5-trisphosphate receptor. Biophys J, 2000, 79: 1388-1399

11 Kagawa Y, Racker E. Partial resolution of the enzymes catalyzing oxidative phosphorylation: XXV. Reconstitution of vesicles catalyzing 32Pi-adenosine triphosphate exchange. J Biol Chem, 1971, 246: 5477-5487

12 Hinkle PC, Kim JJ, Racker E. Ion Transport and respiratory control in vesicles formed from cytochrome oxidase and phospholipids. $\mathbf{J}$ Biol Chem, 1972, 247: 1338-1339

13 Racker E. Reconstitution of a calcium pump with phospholipids and a purified $\mathrm{Ca}^{++}$-adenosine triphosphatase from sarcoplasmic reticulum. J Biol Chem, 1972, 247: 8198-8200

14 Shen HH, Lithgow T, Martin LL. Reconstitution of membrane proteins into model membranes: seeking better ways to retain protein activities. Int J Mol Sci, 2013, 14: 1589-1607

15 Ritchie TK, Grinkova YV, Bayburt TH, Denisov IG, Zolnerciks JK, Atkins WM, Sligar SG. Chapter 11 Reconstitution of membrane proteins in phospholipid bilayer nanodiscs. Methods Enzymol, 2009, 464: $211-231$

16 Näsvik Öjemyr L, Von Ballmoos C, Gennis RB, Sligar SG, Brzezinski P. Reconstitution of respiratory oxidases in membrane nanodiscs for investigation of proton-coupled electron transfer. FEBS Lett, 2012, 586: 640-645

17 Shnyrova AV, Zimmerberg J. Reconstitution of membrane budding with unilamellar vesicles. Methods Enzymol, 2009, 464: 55-75

18 Seddon AM, Curnow P, Booth PJ. Membrane proteins, lipids and detergents: not just a soap opera. Biochim Biophys Acta Biomembr, 2004, 1666: 105-117

19 Pagano A, Spiess M. Reconstitution of Rab4-dependent vesicle formation in vitro. Methods Enzymol, 2005, 403: 81-92

20 Higgins MK, McMahon HT. In vitro reconstitution of discrete stages of dynamin-dependent endocytosis. Methods Enzymol, 2006, 404: 597-611

21 Kano F, Takenaka K, Murata M. Reconstitution of Golgi disassembly by mitotic Xenopus egg extract in semi-intact MDCK cells. Methods Mol Biol (Clifton, NJ), 2006, 322: 357-365

22 Ollivon M, Lesieur S, Grabielle-Madelmont C, Paternostre M. Vesicle reconstitution from lipid-detergent mixed micelles. Biochim Biophys Acta Biomembr, 2000, 1508: 34-50

23 Le Maire M, Champeil P, Møller JV. Interaction of membrane proteins and lipids with solubilizing detergents. Biochim Biophys Acta Biomembr, 2000, 1508: 86-111

24 Garavito RM, Ferguson-Miller S. Detergents as tools in membrane biochemistry. J Biol Chem, 2001, 276: 32403-32406

25 Gohon Y, Popot JL. Membrane protein-surfactant complexes. Curr Opin Colloid Interface Sci, 2003, 8: 15-22

26 Israelachvili JN. Intermolecular and Surface Forces. Burlington, MA: Academic Press, 2011

27 Lévy D, Gulik A, Bluzat A, Rigaud JL. Reconstitution of the sarcoplasmic reticulum $\mathrm{Ca}^{2+}$-ATPase: mechanisms of membrane protein insertion into liposomes during reconstitution procedures involving the use of detergents. Biochim Biophys Acta Biomembr, 1992, 1107: 283-298

28 Young HS, Rigaud JL, Lacapere JJ, Reddy LG, Stokes DL. How to make tubular crystals by reconstitution of detergent-solubilized $\mathrm{Ca}^{2+}$-ATPase. Biophys J, 1997, 72: 2545-2558

29 Seras-Cansell M, Ollivon M, Lesieur S. Generation of non-ionic monoalkyl amphiphile-cholesterol vesicles: evidence of membrane impermeability to octyl glucoside. STP Pharma Sci, 1996, 6: 12-20

30 Holloway PW. A simple procedure for removal of triton X-100 from protein samples. Anal Biochem, 1973, 53: 304-308

31 Zhou X, Graham TR. Reconstitution of phospholipid translocase activity with purified Drs2p, a type-IV P-type ATPase from budding yeast. Proc Natl Acad Sci USA, 2009, 106: 16586-16591

32 Kim M, Song E. Iron transport by proteoliposomes containing mitochondrial F1Fo ATP synthase isolated from rat heart. Biochimie, 2010, 92: 333-342

33 Schaedler TA, Tong Z, van Veen HW. The multidrug transporter LmrP protein mediates selective calcium efflux. J Biol Chem, 2012, 287: 27682-27690

34 Lévy D, Bluzat A, Seigneuret M, Rigaud JL. A systematic study of liposome and proteoliposome reconstitution involving Bio-Beadmediated Triton X-100 removal. Biochim Biophys Acta Biomembr, 
1990, 1025: 179-190

35 Mimms LT, Zampighi G, Nozaki Y, Tanford C, Reynolds JA. Phospholipid vesicle formation and transmembrane protein incorporation using octyl glucoside. Biochemistry, 1981, 20: $833-840$

36 Kasahara M, Hinkle PC. Reconstitution and purification of the D-glucose transporter from human erythrocytes. J Biol Chem, 1977, 252: 7384-7390

37 Israel $\mathrm{M}$, Manaranche $\mathrm{R}$. The release of acetylcholine-from a cellular towards a molecular mechanism. Biol Cell, 1985, 55: 1-14

38 Traikia M, Warschawski DE, Recouvreur M, Cartaud J, Devaux PF. Formation of unilamellar vesicles by repetitive freeze-thaw cycles: characterization by electron microscopy and P-31-nuclear magnetic resonance. Eur Biophys J Biophys Lett, 2000, 29: 184-195

39 Mayer LD, Hope MJ, Cullis PR. Vesicles of variable sizes produced by a rapid extrusion procedure. Biochim Biophys Acta, 1986, 858: 161-168

40 Johnson SM, Bangham AD, Hill MW, Korn ED. Single bilayer liposomes. Biochim Biophys Acta Biomembr, 1971, 223: 820-826

41 Huang $\mathrm{CH}$. Studies on phosphatidylcholine vesicles. Formation and physical characteristics. Biochemistry, 1969, 8: 344-352

42 Lapinski MM, Castro-Forero A, Greiner AJ, Ofoli RY, Blanchard GJ. Comparison of liposomes formed by sonication and extrusion: rotational and translational diffusion of an embedded chromophore. Langmuir, 2007, 23: 11677-11683

43 Bauer PJ, Drechsler M. Association of cyclic GMP-gated channels and $\mathrm{Na}^{+}-\mathrm{Ca}^{2+}-\mathrm{K}^{+}$exchangers in bovine retinal rod outer segment plasma-membranes. J Phys Lond, 1992, 451: 109-131

44 Bucher K, Belli S, Wunderli-Allenspach H, Kramer SD. Pglycoprotein in proteoliposomes with low residual detergent: the effects of cholesterol. Pharm Res, 2007, 24: 1993-2004

45 Berridge MJ, Bootman MD, Roderick HL. Calcium signalling: dynamics, homeostasis and remodelling. Nat Rev Mol Cell Biol, 2003, 4: 517-529

46 Harper JF, Harmon A. Plants, symbiosis and parasites: a calcium signalling connection. Nat Rev Mol Cell Biol, 2005, 6: 555-566

47 Hofer AM, Brown EM. Extracellular calcium sensing and signalling. Nat Rev Mol Cell Biol, 2003, 4: 530-538

48 Orrenius S, Zhivotovsky B, Nicotera P. Regulation of cell death: the calcium-apoptosis link. Nat Rev Mol Cell Biol, 2003, 4: 552-565

49 Simao AM, Yadav MC, Ciancaglini P, Millan JL. Proteoliposomes as matrix vesicles' biomimetics to study the initiation of skeletal mineralization. Braz J Med Biol Res, 2010, 43: 234-241

50 Simao AMS, Bolean M, Hoylaerts MF, Millan JL, Ciancaglini P. Effects of $\mathrm{pH}$ on the production of phosphate and pyrophosphate by matrix vesicles' biomimetics. Calc Tissue Int, 2013, 93: 222-232

51 Simao AMS, Yadav MC, Narisawa S, Bolean M, Pizauro JM, Hoylaerts MF, Ciancaglini P, Millan JL. Proteoliposomes harboring alkaline phosphatase and nucleotide pyrophosphatase as matrix vesicle biomimetics. J Biol Chem, 2010, 285: 7598-7609

52 Zayas C, Gonzalez D, Acevedo R, del Campo J, Lastre M, Gonzalez E, Romeu B, Cuello M, Balboa J, Cabrera O, Guilherme L, Perez O. Pilot scale production of the vaccine adjuvant proteoliposome derived cochleates (AFCo1) from Neisseria meningitidis serogroup B. BMC Immunol, 2013, 14(Suppl 1): S4

53 Acevedo R, Perez O, Zayas C, Perez JL, Callico A, Cedre B, Garcia L, McKee D, Mullen AB, Ferro VA. Cochleates derived from Vibrio cholerae $\mathrm{O} 1$ proteoliposomes: the impact of structure transformation on mucosal immunisation. PLoS One, 2012, 7: e46461

54 Guilherme L, Postol E, de Barros SF, Higa F, Alencar R, Lastre M, Zayas C, Puschel CR, Silva WR, Sa-Rocha LC, Sa-Rocha VM, Perez O, Kalil J. A vaccine against $S$. pyogenes: design and experimental immune response. Methods, 2009, 49: 316-321

55 Acevedo R, Callico A, del Campo J, Gonzalez E, Cedre B, Gonzalez L, Romeu B, Zayas C, Lastre M, Fernandez S, Oliva R, Garcia L, Luis Perez J, Perez O. Intranasal administration of proteoliposomederived cochleates from Vibrio cholerae O1 induce mucosal and systemic immune responses in mice. Methods, 2009, 49: 309-315

56 Perez O, Lastre M, Cabrera O, del Campo J, Bracho G, Cuello M, Balboa J, Acevedo R, Zayas C, Gil D, Mora N, Gonzalez D, Perez R, Gonzalez E, Barbera R, Fajardo EM, Sierra G, Solis RL, Campa C. New vaccines require potent adjuvants like AFPL1 and AFCo1. Scand J Immunol, 2007, 66: 271-277

57 Sobel A, Weber M, Changeux J-P. Large-scale purification of the acetylcholine-receptor protein in its membrane-bound and detergent-extracted forms from Torpedo marmorata electric organ. Eur J Biochem, 1977, 80: 215-224

58 Epstein M, Racker E. Reconstitution of carbamylcholine-dependent sodium ion flux and desensitization of the acetylcholine receptor from Torpedo californica. J Biol Chem, 1978, 253: 6660-6662

59 Schiebler W, Hucho F. Membranes rich in acetylcholine receptor: characterization and reconstitution to excitable membranes from exogenous lipids. Eur J Biochem, 1978, 85: 55-63

60 Ramos J, Jung WY, Ramos-Franco J, Mignery GA, Fill M. Single channel function of inositol 1,4,5-trisphosphate receptor type-1 and-2 isoform domain-swap chimeras. J Gen Physiol, 2003, 121: 399-411

61 Mignery GA, Johnston PA, Südhof TC. Mechanism of $\mathrm{Ca}^{2+}$ inhibition of inositol 1,4,5-trisphosphate (InsP3) binding to the cerebellar InsP3 receptor. J Biol Chem, 1992, 267: 7450-7455

62 Kameyama A, Shearman MS, Sekiguchi K, Kameyama M. Cyclic AMP-dependent protein kinase but not protein kinase $\mathrm{C}$ regulates the cardiac $\mathrm{Ca}^{2+}$ channel through phosphorylation of its alpha(1) subunit. J Biochem, 1996, 120: 170-176

63 Navarro J, Pyun HY, Essig A. Voltage-dependence of phosphoenzyme formation of reconstituted $\mathrm{Ca}^{2+}$-ATPase vesicles. Biophys $\mathrm{J}$, 1985, 47: A345-345

64 Cheng KH, Lepock JR, Hui SW, Yeagle PL. The role of cholesterol in the activity of reconstituted Ca-ATPase vesicles containing unsaturated phosphatidylethanolamine. J Biol Chem, 1986, 261: 5081-5087

65 Wakabayashi S, Shigekawa M. Rapid reconstitution and characterization of highly-efficient sarcoplasmic-reticulum Ca pump. Biochim Biophys Acta, 1985, 813: 266-276

66 Moffett S, Brown DA, Linder ME. Lipid-dependent targeting of G proteins into rafts. J Biol Chem, 2000, 275: 2191-2198

67 Dalziel JE, Wong SS, Phung T, Zhang YL, Dunlop J. Expression of human BK ion channels in Sf9 cells, their purification using metal affinity chromatography, and functional reconstitution into planar lipid bilayers. J Chromatogr B Anal Technol Biomed Life Sci, 2007, 857: $315-321$

68 Weber T, Zemelman BV, McNew JA, Westermann B, Gmachl M, Parlati F, Söllner TH, Rothman JE. SNAREpins: minimal machinery for membrane fusion. Cell, 1998, 92: 759-772

69 Nickel W, Weber T, McNew JA, Parlati F, Sollner TH, Rothman JE. Content mixing and membrane integrity during membrane fusion driven by pairing of isolated v-SNAREs and t-SNAREs. Proc Natl Acad Sci USA, 1999, 96: 12571-12576

70 Liu TT, Tucker WC, Bhalla A, Chapman ER, Weisshaar JC. SNARE-driven, 25-millisecond vesicle fusion in vitro. Biophys J, 2005, 89: 2458-2472

71 Cho WJ, Shin L, Ren G, Jena BP. Structure of membrane-associated neuronal SNARE complex: implication in neurotransmitter release. J Cell Mol Med, 2009, 13: 4161-4165

Open Access This article is distributed under the terms of the Creative Commons Attribution License which permits any use, distribution, and reproduction in any medium, provided the original author(s) and source are credited. 